\title{
NON-DESTRUCTIVE TESTING OF TENNIS STRINGS
}

\author{
Luong Minh Phong \\ CNRS-LMS, Ecole Polytechnique, Palaiseau France
}

\begin{abstract}
The paper aims to illustrate three advantages of infrared thermography as a non-destructive, non-contact and in real time technique (a) to detect the occurrence of intrinsic dissipation localisation, (b) to observe the progressive damage processes and mechanisms of gut failure, and to determine the optimal tensions for each type of tennis strings. Experimental results evidence a limit of acceptable damage beyond which string will fail due to coalescence of defects and/or weakness zones.
\end{abstract}

\section{INTRODUCTION}

Sports engineering covers various research themes in design, materials and sport, biomechanics, instrumentation, modelling, mechanics, motion analysis, dynamics, etc. In all these areas, thermal aspects should not be ignored because they help identify different product attributes for better competitive sports performance, style, comfort, safety and enjoyment [1]. This leads to an increasing requirement for appropriate testing (1) to ensure product integrity and reliability, (2) to avoid failure, (3) to aid in better product design, (4) to control manufacturing processes, etc.

Damage and failure behaviour of natural gut string and others types of tennis racket strings in synthetic products are an important consideration for skilled tennis players who should be extremely aware of their equipment's performance relative to their personal needs and game style. What mechanical performance in string tensions that will best fit the player's requirements? Borg strung his rackets at 80 pounds $(367 \mathrm{~N})$ and his strings often broke from the high tension. In contrast, McEnroe chose 48 pounds (220N) for stringing his rackets. Commonly the recommendations are in a range of about 55 to 65 pounds (250-295N). The tension is very important as it has a direct effect on power and control. As a general rule, the looser the tension, say in the 50-pound range, the less control the player has. The racket acts more like a trampoline and the ball may fly off the strings and appear to have more speed. Tighter strings, say in the 60-pound range, will give more control over the shot. Professionals often string their rackets in the 70-pound range. This gives them a lot of control but the strings break more often. Much engineering research has been conducted to determine optimal string tension for different size rackets made from various types of materials [2].

The limit of acceptable damage in tension for most of these tennis strings probably lies between these two values. This work proposes to determine objectively this tension threshold from the material point of view, using an infrared thermographic technique. 
It may suggest material optimisation of string products for manufacturers. In addition this technique can be used as a non-destructive, non-contact and in real-time method for inspection and ready evaluation of stress concentration in strung rackets.

This work considers the intrinsic dissipation, generated by plasticity, as a highly sensitive and accurate indicator of damage manifestation. Thanks to the thermomechanical coupling [3], infrared thermography is used to observe the physical processes of damage and to detect the onset and the evolution of damage and failure processes of tennis string when the specimen is subjected to increasing tensile loading. It readily gives a measure of the material damage and permits evaluation of the limit of a progressive damaging process under tension beyond which the material fails.

\section{TESTING METHOD}

Infrared thermography is a convenient technique for producing heat images from the invisible radiant energy emitted from stationary or moving objects at any distance and without surface contact or in any way influencing the actual surface temperature of the objects viewed. The temperature rise ahead of a fatigue crack has been measured using a thermographic camera [4] in order to demonstrate the local heating at the tip. Attempts have been made to measure and characterise the heat generated during the cyclic straining of composite materials [5]. The scanning infrared camera has been used to visualise the surface-temperature field on steel and fiberglass-epoxy composite samples during fatigue tests [6]. Recently this infrared thermographic technique has been applied in sport engineering [7-8].

In this work, the scanning camera is analogous to a television camera. It uses an infrared detector in a sophisticated electronics system in order to detect radiated energy and to convert it into a detailed real-time thermal image in a colour and monochrome video system. Response times are shorter than one microsecond. Temperature differences in the heat patterns are discernible instantly and represented by several distinct hues. The quantity of energy $W\left(W \mathrm{~m}^{-2} \mu \mathrm{m}^{-1}\right)$, emitted as infrared radiation, is a function of the temperature and emissivity of the specimen. The higher is the temperature, the more important the emitted energy. Differences of radiated energy correspond to differences of temperature.

Since the received radiation has a non-linear relationship to the object's temperature, and can be affected by atmospheric damping and includes reflected radiation from object's surroundings, calibration and correction procedures have to be applied. Knowing the temperature of the reference, the object's temperature can then be calculated with a sensitivity of $0.1^{\circ} \mathrm{C}$ at $20^{\circ} \mathrm{C}$. The infrared scanner unit converts electromagnetic thermal energy radiated from the tested specimen into electronic video signals. These signals are amplified and transmitted via an interconnecting cable to a display monitor where the signals are further amplified and the resultant image is displayed on the screen.

\section{RESULTS}

Mechanical properties of tennis racket strings are mainly dependent on its type (natural gut, artificial gut, nylon, graphite string, synthetic products, etc.), nature and 
structure. Manufacturers give players a choice of string styles. The higher is the number, the thicker the gauge of the string. Consumers can choose 15-gauge, 16-gauge, 17-gauge, 18-gauge and even 19-gauge strings: the lower the gauge number, the lighter the string. Lower gauge strings, like 16, last longer and are good for players who hit with a lot of spin. Thinner gauges of string are livelier and can impart more ball spin but likely break sooner. This fact suggests that there is an instantaneous non-linear phenomenon creating large displacements and large deformations due to Coulomb friction at string nodes: wear by fretting. This aspect will be examined hereafter in the case of natural gut. Better players like to use 17-gauge or 18-gauge as this gives them more touch and feel.

The effect of varying string tensions is important to skilled players wanting to improve their shot velocity and control [9]. The looser are the strings (within the recommended range), the higher the ball velocity after impact [10]. When string is loaded, it deforms as a whole in spite of its heterogeneous characteristics and its localised defects. Stress concentrations occur and result in localised forces that are sufficient to promote plasticity and inelasticity. At the structural level, breakdown appears as micro cracking and possibly slippage at component interfaces.

Failure mechanisms of string specimens subject to tensile loading are readily evidenced by infrared thermography in this work. Uniaxial tensile tests were carried out for 2 types of tennis strings: natural gut and synthetic fibres.

\section{NATURAL GUT STRING}

Gut is a natural animal fibre, manufactured from the smooth muscle portion of sheep or beef intestines (Figure 1) through sophisticated chemical process of washing, bleaching, twisting, drying, and refining to ensure strength and uniformity [11]. When loaded in tension (2a), natural gut string undergoes plasticity (2b-2c) that is detected by infrared thermography. Subtractions of raw thermal images at tension levels $\mathrm{T}_{2}$ and $\mathrm{T}_{3}$ and a reference tension level $\mathrm{T}_{1}$ evidence dissipative phenomenon $(2 \mathrm{~d}-2 \mathrm{e})$ between these tension levels that locates the failure of gut string. When tensile loading is applied up to failure (Figure 3), the evolution of dissipation suggests the definition of a limit of acceptable damage $\mathbf{L A D}$ that separates low and high regimes of dissipation or damage manifestation (Fig. 4).

\section{SYNTHETIC STRING}

Material composites have increased the diversity of design and manufacturing for sports products. There are a large variety of synthetic products (Figure 5) including nylon, artificial gut, graphite string, oil-filled string, etc. Very specific designs are targeted to match the physical capability of each player. Can their mechanical performance be characterised in term of damage and durability? In the interaction of the ball and the strings, the kinetic energy of the ball is converted into potential energy stored in both ball and string deformation. By storing a larger fraction of the incoming energy in the strings, less is dissipated, and more is returned to the ball's rebounding kinetic energy. The shock vibrations of the wrist joint are transmitted from the racket with an impulse at the impact location and several vibration mode components of the racket frame and strings [12]. The 

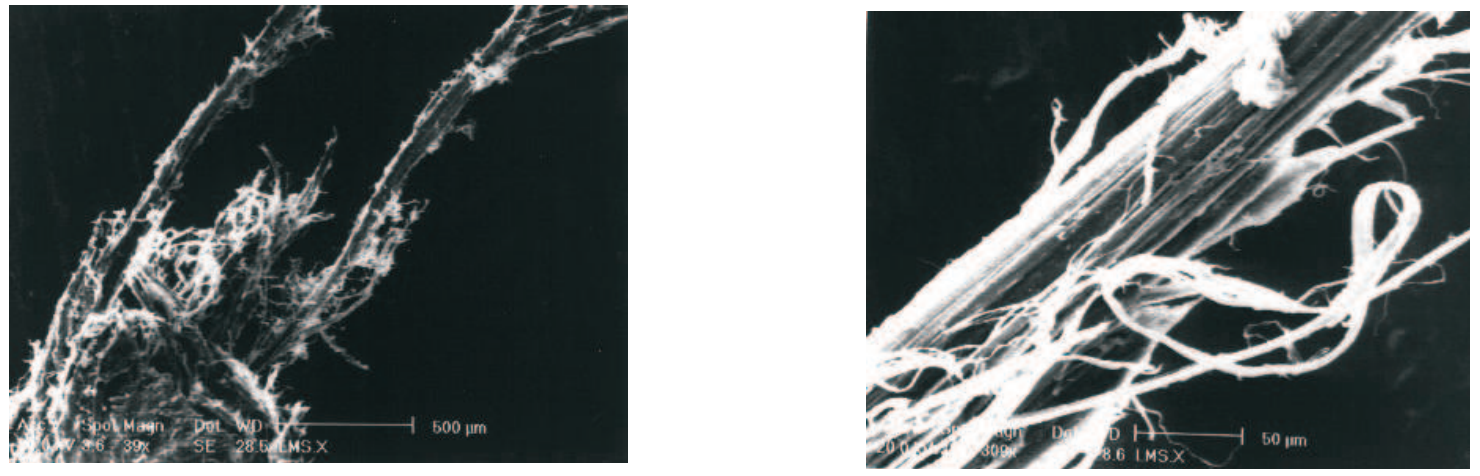

Fig. 1. Natural gut string at different scales of observation

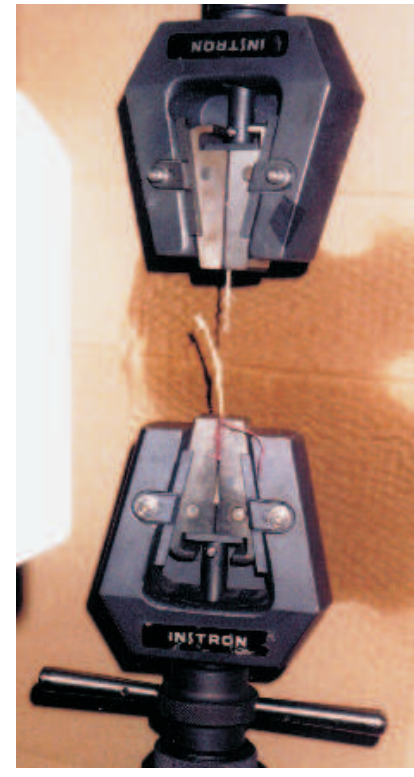

(2a)

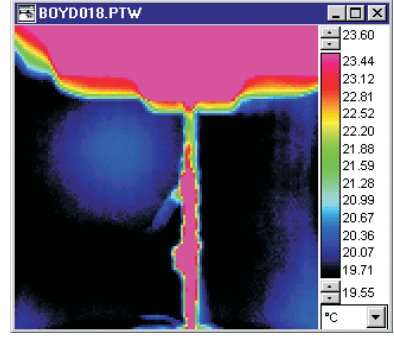

(2b)

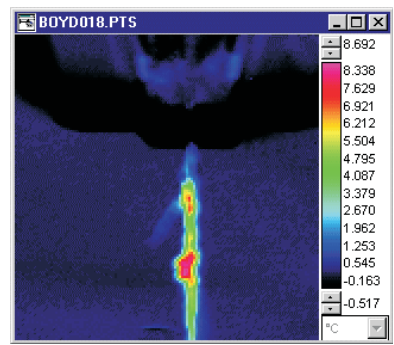

(2bd)

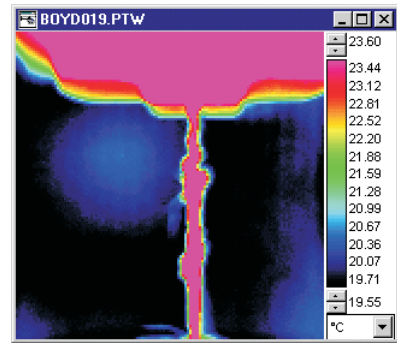

$(2 \mathrm{c})$

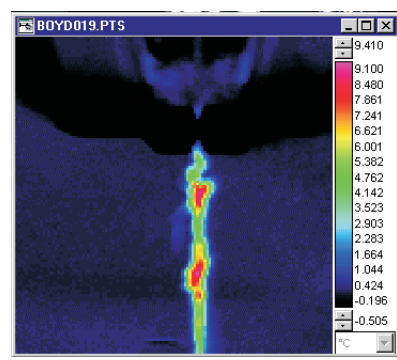

$(2 \mathrm{~cd})$

Fig. 2. Tension on natural gut string (2a): raw thermal images (2b-2c) at different tensile levels preceding failure and their corresponding dissipation localisations (2bd-2cd). Temperatures and temperature changes are given in Celsius degrees

higher are the string tensions, the higher the vibration frequency. This fact influences the feel or comfort of the arm or hand in an impact. As tension increases, the elasticity of these materials degrades. Dissipation occurs and infrared thermography readily detects the manifestation of damage (Figure 6). As with natural gut, when tensile loading is applied 


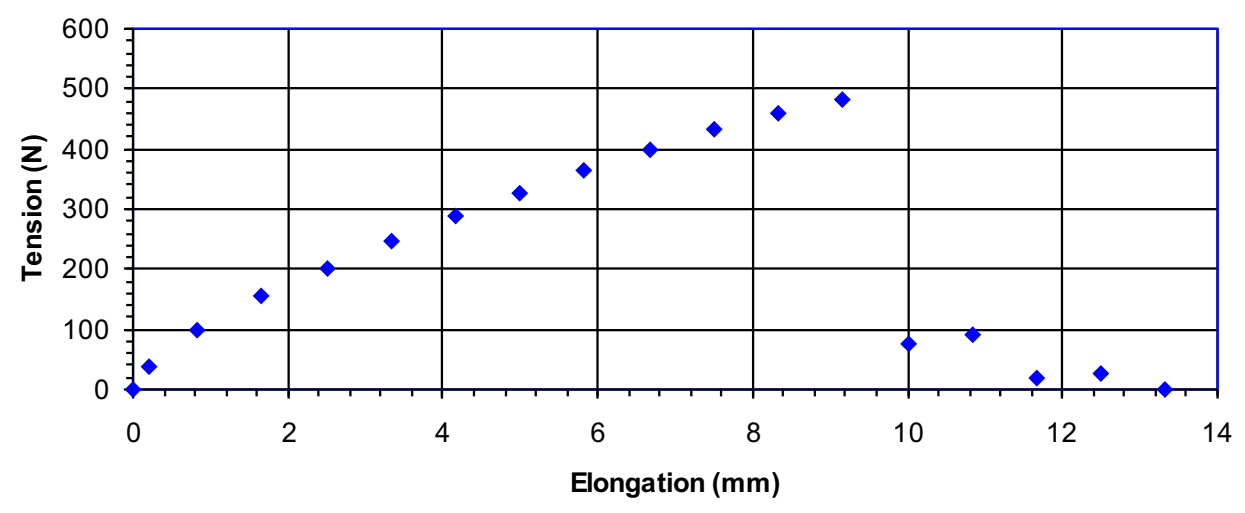

Fig. 3. Tension-elongation curve of a natural gut string subjected to tensile loading up to failure

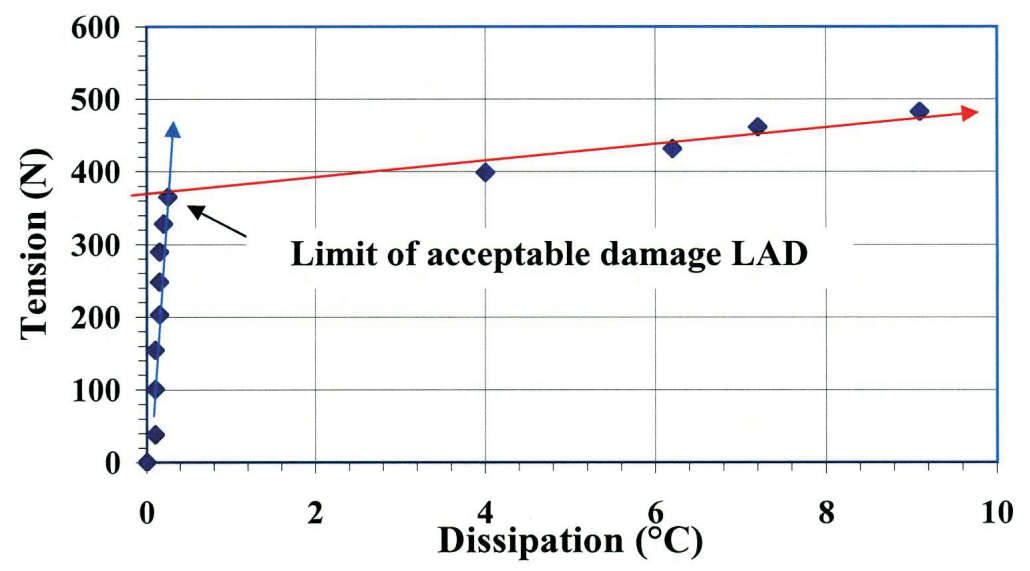

Fig. 4. Damage behaviour evaluation of a natural gut string in tension and graphical determination of the limit of acceptable damage LAD

up to failure an LAD (limit of acceptable damage) is suggested, separating low and high regimes of dissipation or damage.

\section{DRY SLIDING OF NATURAL GUT STRING AT NODES}

In order to produce ball spin in tennis, the player must accelerate the racket head through impact to brush the backside of the ball: (i) upward for topspin, (ii) downward for underspin and (iii) sideways for sidespin. The more vertical (or horizontal) the racket swings (in either direction), the more ball spin will be produced. The amount of spin a player imparts on the ball, combined with a high stroke velocity, generates dry sliding between longitudinal and transverse strings at nodes located in the racket's effective hitting zone. Relative movements between longitudinal and transverse strings occur depending on 


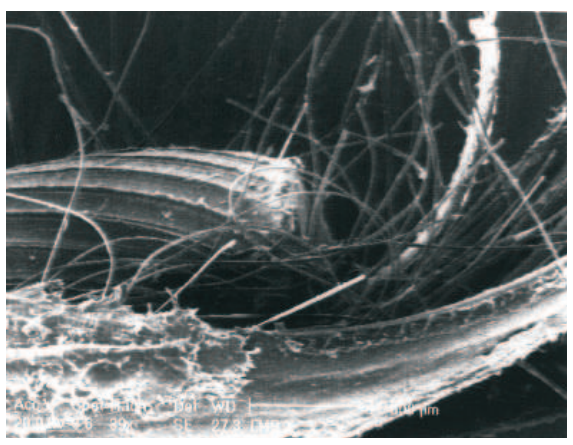

(5a)

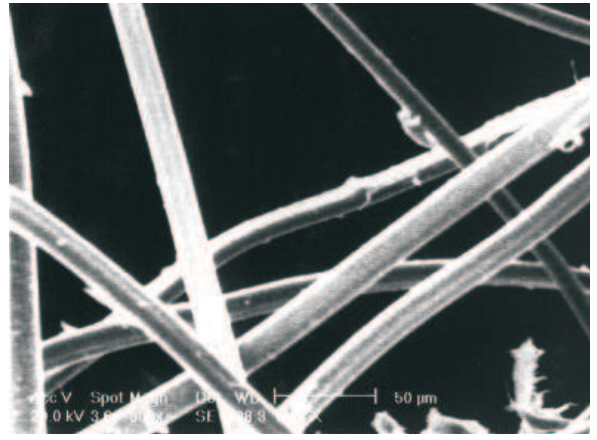

$(5 b)$

Fig. 5. Synthetic fibres string at different scales of observation

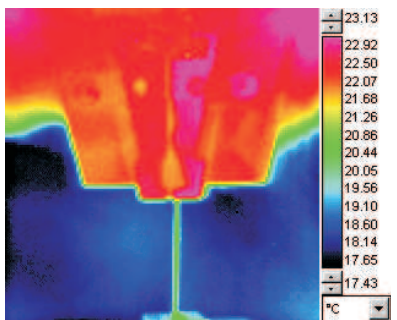

(6a)

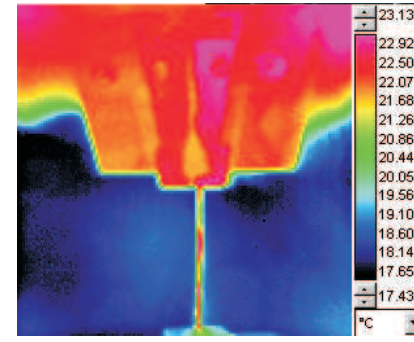

$(6 \mathrm{ad})$

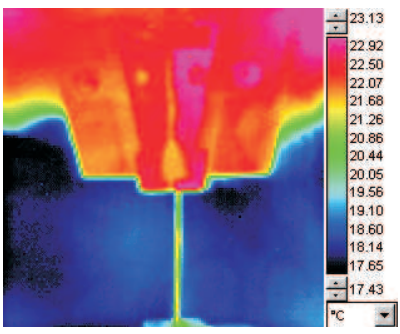

(6b)

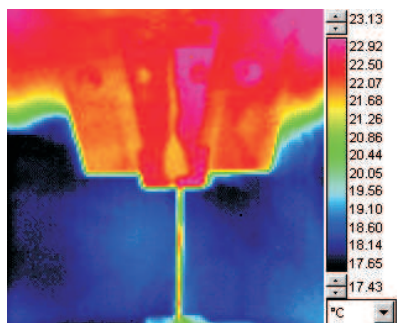

$(6 \mathrm{c})$

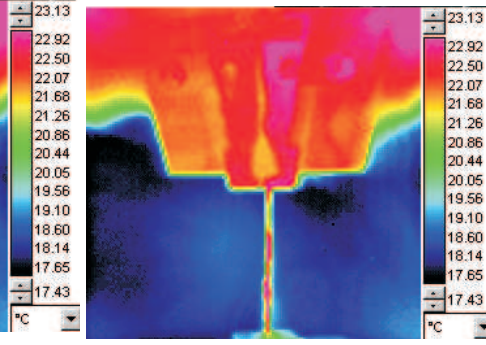

$(6 \mathrm{bd})$

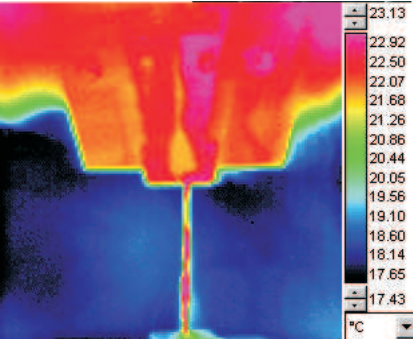

$(6 \mathrm{~cd})$

Fig. 6. Successive thermal images at different tensile levels (6a-6b-6c) preceding failure and their corresponding dissipation locations (6ad-6bd-6cd). Temperatures and temperature changes are given in Celsius degrees

the type of ball-racket impact. They lead to tribological phenomena, such as friction, wear, pitting and fretting fatigue. 
Fretting is a major problem in optimising tennis strings. It is defined as the surface damage induced by small-amplitude oscillatory displacements between strings in contact. This damage can either be wear or crack nucleation, depending on the prescribed forces or the displacement amplitude. Infrared thermography has been used to estimate tribological parameters, such as a frictional temperature rise, the shape and the size contact of the contact area. We consider a contact problem, in which a moving longitudinal string (9cm long) is in contact with a fixed transverse string ( $5 \mathrm{~cm}$ long). The two strings were initially stretched at $200 \mathrm{~N}$. An electromagnetic vibrator at a frequency of $1 \mathrm{~Hz}$ controls the cyclic motion of the longitudinal string. Force sensors respectively measure the normal and tangential contact forces (Figure 7). Infrared thermography readily detects heat dissipation by Coulomb friction at contact location where sliding occurs between longitudinal and transverse gut strings in the following cases: initial normal contact force $\mathrm{NCF}=50 \mathrm{~N}$ (Figure 8).

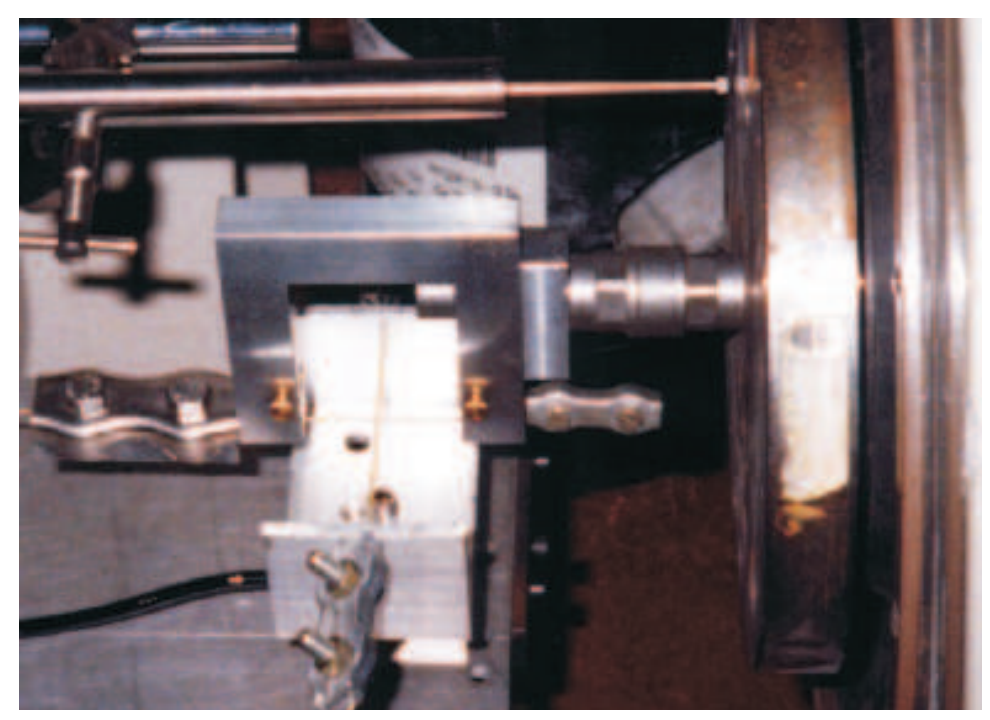

Fig. 7. Experimental set-up for fretting fatigue testing on natural gut string at nodes

The experimental data demonstrate that wear phenomena occurring in tennis rackets could be of interest in case of long matches such as the men's final of 1988 US open Tennis Tournament Lendl versus Wilander (4 hours, 54 minutes with several thousands of strokes). The main parameters identified are string tension, racket stiffness, effects of spin, hitting power, etc.

This work has demonstrated that the dissipativity of tennis string material under tension or frictional loading is highly sensitive and is an accurate predictor of damage. Owing to the thermomechanical coupling, infrared thermography offers the possibility of a non-destructive, non-contact testing of string degradation and damage. It provides a ready evaluation of a limit of fretting fatigue load (Figure 9), beyond which the string will fail in a long match. The opportunities offered by thermal techniques with remote operation and fast surface-scanning rates are particularly attractive for sports equipment. 


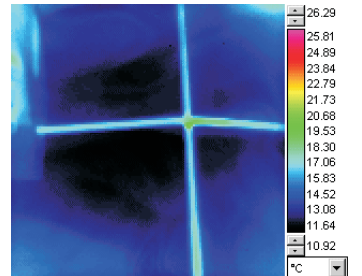

$1^{\text {st }}$ load cycle

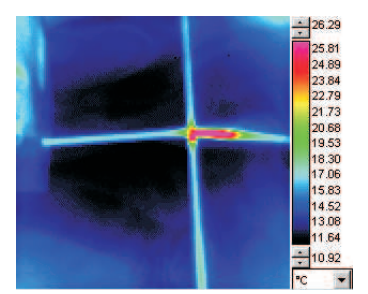

10 load cycles

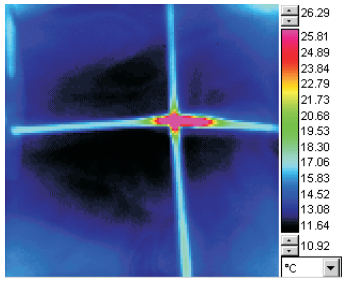

20 load cycles

Fig. 8. Evolution of the heat dissipation by dry sliding between vertical and horizontal strings with the number of load cycles (initial normal contact force $=50 \mathrm{~N}$ ). Temperatures are given in Celsius degrees

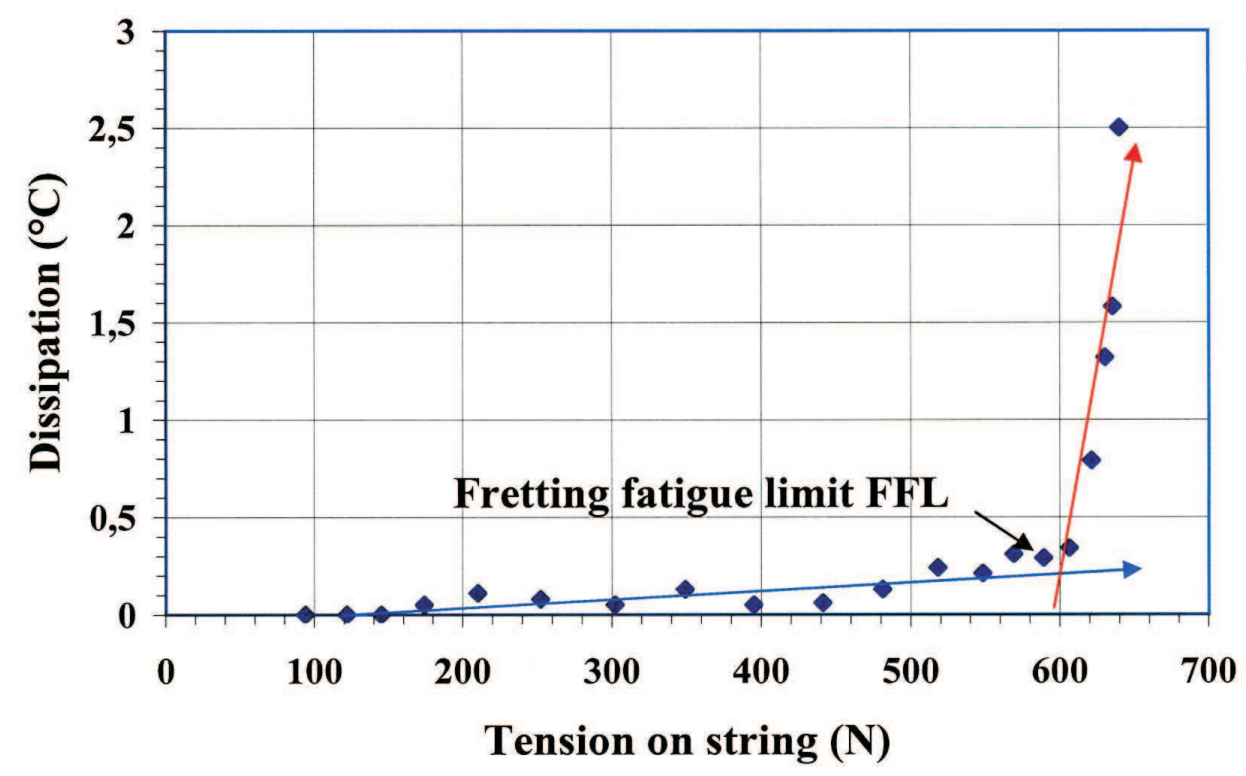

Fig. 9. Graphical determination of fretting fatigue limit FFL of a natural gut string using infrared thermography

\section{CONCLUSION}

This work has demonstrated that the dissipativity of tennis string material under tension or frictional loading is a highly sensitive and accurate manifestation of damage. The opportunities offered by thermal techniques with remote operation and fast surfacescanning rates are particularly attractive for sports equipment.

The main interest of this energy approach is to unify microscopic and macroscopic test data. The parameter intrinsic dissipation under consideration is a scalar quantity, easy to evaluate accurately. Subsequently it may suggest multiaxial design criteria, highly relevant for full-scale testing on engineering structures. 


\section{REFERENCES}

[1] P. Taylor, The economics of the sports products industry, The Engineering of Sport - Design and Development, ed. S. Haake, Oxford, Blackwell Publishing, 3-12, 1998.

[2] J. L. Groppel, I. S. Shin, J. A. Thomas \& G. J. Welk, . The effects of string type and tension on impact in midsized and oversized tennis racquets, International Journal of Sport Biomechanics 3 (1987) 40-46.

[3] M. P. Luong, Infrared thermography of macrostructural aspects of thermoplasticity, Microand Macrostructural Aspects of Thermoplasticity, ed. by Bruhns \& Stein, Kluwer Academic Publishers, Solid Mechanics and its Applications, 62 (1999) 437-446.

[4] R. Attermo \& G. Östberg, Measurements of the temperature rise of a fatigue crack, International Fracture Mechanics 7 (1971) 122-124.

[5] K. L. Reifsnider \& R. S. Williams, Determination of fatigue-related heat emission in composite materials, Experimental Mechanics 14 (1974) (12) 479-485.

[6] J. A. Charles, F. J. Appl \& J. E. Francis, Using the scanning infrared camera in experimental fatigue studies, Experimental Mechanics 14 (1975) (4) 133-138.

[7] M. P. Luong, D. Parganin \& J. Loizeau, Non destructive detection of damage in soccer balls using infrared thermography, The Engineering of Sport, ed. by Haake, Blackwell Science, ISBN 0-632-05048-9, 145-152, 1998.

[8] D. Parganin, M. P. Luong \& J. Loizeau, Infrared scanning of damage in sail materials, The Engineering of Sport, ed. by Haake, Blackwell Science, ISBN 0-632-05048-9, 163-170, 1998.

[9] J. L. Groppel, High Tech Tennis, Leisure Press, Champaign, Illinois, $\mathbf{2}^{\text {nd }}$ Edition, ISBN 0-88011-458-4, 1992.

[10] H. Brody, The modern tennis racket, The Engineering of Sport, ed. by Haake, 1996 Balkema, ISBN 905410822 3, 79-82, 1996.

[11] D. L. Babolat Squash, Tennis, Badminton, $C H / F / B, 2-14,1996$.

[12] Y. Kawazoe, R. Tomosue \& K. Yoshinari, Performance prediction of tennis rackets with different racket head size: impact shock vibrations of a racket grip and a player's wrist joint, The Engineering of Sport, ed. by Haake, 1998 Blackwell Science, ISBN 0-632-05048-9, 325$332,1998$.

Received April 21, 2009

\section{KIỂM TRA KHÔNG PHÁ HỦY SƠI CĂNG VỢT TENNIS}

Mục đích của bài báo là trình bày ba ưu điểm của đồ họa nhiệt như một kỹ thuật không phá hủy, không tiếp xúc và trong miền thời gian thực (a) để phát hiện sự xuất hiện của hiện tượng phân tán vi trí ở bên trong, (b) quan sát quá trình phát thiển của hư hỏng và cơ chế phá hủy của sợi gut và xác định độ căng tối ưu cho tường loại dây căng vợt tennis. Kết quả thí nghiệm chỉ ra một tập hợp các hư hỏng có thể chấp nhận được, ngoài những hư hỏng này dây căng vợt có thể sẽ bị hỏng do tổ hợp các khuyết tật hay do vùng yếu. 